\title{
Review Article \\ Therapeutic Role of Functional Components in Alliums for Preventive Chronic Disease in Human Being
}

\author{
Yawen Zeng, ${ }^{1}$ Yuping Li, ${ }^{2}$ Jiazhen Yang, ${ }^{1,3}$ Xiaoying Pu, ${ }^{1}$ Juan Du, ${ }^{1}$ Xiaomeng Yang, \\ Tao Yang, ${ }^{1}$ and Shuming Yang ${ }^{1}$ \\ ${ }^{1}$ Biotechnology and Genetic Resources Institute, Yunnan Academy of Agricultural Sciences/Agricultural Biotechnology Key Laboratory \\ of Yunnan Province, Kunming 650205, China \\ ${ }^{2}$ Yuxi Agriculture Vocation-Technical College, Yunnan, Yuxi 653106, China \\ ${ }^{3}$ Kunming Tiankang Science \& Technology Limited Company, Yunnan, Kunming 650231, China
}

Correspondence should be addressed to Yawen Zeng; zengyw1967@126.com

Received 24 November 2016; Accepted 11 January 2017; Published 5 February 2017

Academic Editor: Filippo Fratini

Copyright (c) 2017 Yawen Zeng et al. This is an open access article distributed under the Creative Commons Attribution License, which permits unrestricted use, distribution, and reproduction in any medium, provided the original work is properly cited.

\begin{abstract}
Objectives. Functional components in alliums have long been maintained to play a key role in modifying the major risk factors for chronic disease. To obtain a better understanding of alliums for chronic disease prevention, we conducted a systematic review for risk factors and prevention strategies for chronic disease of functional components in alliums, based on a comprehensive English literature search that was conducted using various electronic search databases, especially the PubMed, ISI Web of Science, and CNKI for the period 2007-2016. Allium genus especially garlic, onion, and Chinese chive is rich in organosulfur compounds, quercetin, flavonoids, saponins, and others, which have anticancer, preventive cardiovascular and heart diseases, anti-inflammation, antiobesity, antidiabetes, antioxidants, antimicrobial activity, neuroprotective and immunological effects, and so on. These results support Allium genus; garlic and onion especially may be the promising dietotherapeutic vegetables and organopolysulfides as well as quercetin mechanism in the treatment of chronic diseases. This review may be used as scientific basis for the development of functional food, nutraceuticals, and alternative drugs to improve the chronic diseases.
\end{abstract}

\section{Introduction}

Natural products, which associate with health foods for plant origin centers, are very popular to prevent various chronic diseases. Asia is one of the origin centers of Allium genus, especially garlic (Allium sativum L.), onion (Allium cepa L.), and Chinese chive (Allium tuberosum) [1]; however sulfur compounds from alliums have played a key roles in defense [2]. Sulfur is the component of some amino acids and Fe$S$ clusters for enzymes activity [3]. Fe-S clusters are very important for origin of life, especially acetyl-CoA, DNA, and RNA world [4]. Chronic diseases are a serious threat to human health and economic growth; however the costs of five chronic diseases (cardiovascular diseases, cancers, diabetes, chronic respiratory disease, and mental illness) will be over US $\$ 47$ trillion from 2011 to $2030[5,6]$. Garlic, which was one of the best foods for preventing chronic disease, has been utilized in treating human diseases since 5000 years
[7-9]. The high consumption of Allium genus reduced the risk for various cancers [10, 11]. Allium oils had the highest antibacterial activity or the strongest antioxidants [12]. The consumption of onion extract had better cardioprotective effect by antioxidation and anti-inflammation, attenuating cholesterol and cardiovascular disease [13].

It is known that Allium genus are widely cultivated and used all over the world, particularly garlic, onion, shallot (Allium ascalonicum), leek (Allium ampeloprasum), and chive (Allium schoenoprasum) [14]. The edible species of Allium L. in China included 68 species and 6 varieties, from which there are 7 cultivated species and 2 varieties and 61 wild species and 4 varieties [15]. China is not only the largest production and export but also the consumer country for garlic and onion in the world, such as the annual output and export of garlic accounted for more than $70 \%$ of the world. Chinese chive is widely cultivated in Asia especially China, from which 2,125 
SSRs are identified, which will facilitate its genetic research [16].

Our review is an overview on the scientific literature concerning the effects of functional components in Allium genus especially garlic and onion in the prevention or treatment of chronic disease in Human Being.

\section{Functional Components in Alliums}

Functional components of food can be applied in the treatment and prevention of chronic diseases; they include nonstarchy carbohydrates (dietary fibres, resistant starch, and fucoidan), antioxidants (organosulfur compounds, polyphenols, carotenoids, tocopherols, tocotrienols, phytosterols, and isoflavones), unsaturated fatty acids, bioactive peptides, sterols, and phytoestrogens [17]. Allium genus is rich in sulfur compounds, steroidal saponins, flavonoids, and so on, which have anticancer, antioxidant, antiplatelet aggregation, antiatherosclerosis, antimicrobial, and lower blood lipids and blood glucose biological activity. S-alk(en)yl-l-cysteine sulfoxides are cysteine-derived secondary metabolites highly accumulated in the genus Allium [18]. Structures of 15 major color compounds of onion and leek were determined; the pigment is a complex mixture of highly conjugated species composed of two $\mathrm{N}$-substituted 3,4-dimethylpyrrole-derived rings linked by bridge from the methyl group of methiin or propenyl group of isoalliin [19].

2.1. Garlic. Garlic is a very important source of dietary for antioxidant properties, including sulfur compounds, polyphenols, and carotenoids. Garlic contains sulfur compounds like diallyl thiosulfinate (allicin), diallyl trisulfide, allyl methyl trisulfide, diallyl disulphide, ajoene, and others, which show anticancer, antioxidation, anti-inflammation, immunomodulatory, antimicrobial, hypoglycemic, and cardiovascular protections [20]. Allicin from garlic with many biological activities is a consequence of the molecule's chemistry [21]. Garlic has four major organosulfur compounds: $S$-allylcysteine, alliin, $S$-methylcysteine, and $S$-ethylcysteine [7]. S-allylcysteine has antioxidation, regulated redox, antiapoptotic, anti-inflammation, proenergetic, and signaling capacities [22]; however it ameliorates lots of diseases [23]. $S$-allylmercaptocysteine with anticancer activity inhibits the growth of cancer cells [24]. Diallyl disulfide can prevent tumorigenesis by inhibiting inflammation and GSK-3 $\beta$ [25] as well as NF- $\kappa$ B mediated pathway in human leukemia [26]. $S$-propargyl-cysteine, a structure of analog $S$-allylcysteine, will be discovered in chronic diseases because it activated antioxidation, inhibited STAT3, elevated p53/Bax, and decreased $\mathrm{Ca}^{2+}$ accumulation and inflammatory cytokines [27]. Garlic reduces the risks of cardiovascular disease by inhibiting platelet aggregation and lowering cholesterol and blood pressure, based on the fact that allicin (diallyl thiosulfinate) is degraded into diallyl polysulfides by $\mathrm{H}_{2} \mathrm{~S}$ preventing myocardial injury and dysfunction [9]. AsFMO1 in garlic for $S$-allyl-L-cysteine $S$-oxygenase contributes to the production of alliin through the conversion and biosynthesis of $\gamma$-glutamyl-S-allyl-L-cysteine in storage leaves [18]. The antiwrinkle for skin aging of caffeic acid, $S$-allyl cysteine, and uracil associated with antioxidation and anti-inflammation by modulating MMP via NF- $\kappa$ B signaling [28]. The $S$-ethyl cysteine or $S$-methyl cysteine can protect bronchial cells and respiratory epithelia [29]. Chemical constituents of garlic were alliin $(0.320 \%)$, allicin $(0.273 \%)$, and allitride $(0.357 \%)$ [30]. The black garlic allicin had the function of reducing blood glucose, and the main function of substance contained 7 sulfide materials, in which the total content was $2.279 \%$ [31]. In garlic, cycloalliin level at $80^{\circ} \mathrm{C}$ showed the highest yield $(5.05 \mathrm{mmol} / \mathrm{mL})$, among the tested temperatures [32]. Sucrose methyl 3-formyl-4-methylpentanoate from garlic has antimicrobial activities by enhanced microbial killing and blockage of cytokine storm [33]. The glycoprotein from ripe garlic has potential uses in functional foods and medical applications by the 1,1-diphenyl-2-picrylhydrazil free radical scavenging activity and polyunsaturated fatty acid inhibiting ability [34]. $\beta$-Carotene $(73.44 \mu \mathrm{g} / \mathrm{g})$ accumulation in the leaves of garlic with synthase and desaturase of phytoene is a significantly higher than that of other organs [35]. The garlic bulbs extract had ten furostanol saponins, ten types of voghierosides, two eugenol diglycosides, agigenin 3-Otrisaccharide, and gitogenin 3-O-tetrasaccharide [36].

2.2. Onion. Onion (Allium cepa) is an important source of dietary phytochemicals with proven antioxidant properties, such as organosulfur compounds, phenolic acids, flavonoids, thiosulfinates, and anthocyanins. 30 compounds from volatiles compounds of black onion were identified, which accounted for $52.63 \%$ of all compounds and $81.69 \%$ of the total peak areas; these components included 19 sulfur-containing volatiles compounds, such as diallyl sulfide, methyl allyl sulfide, 3-hydroxysulfolane, 2,4dimethylthiophene, 2-methoxythiophene, 1,4-dithiane, and 1,3-dithiane [37]. A total of 49 types of volatile compounds were identified from onion, which were mainly sulfur compounds, alcohols, aldehyde, ester, and other chemical groups, but there was significant difference in volatile compound pattern and their relative contents from fresh and dried onion [38]. The diabetic rats supplemented with either onion or with single components (alliin, allitride, and $S$-methylcysteine sulfoxide) possess lowering plasma glucose concentrations and body weight [39] and preventive cardiovascular diseases. The major components of onion were quercetin, quercetin glucosides, isorhamnetin glucosides, and kaempferol glucoside; their concentrations in Tropea were 20-230-fold higher than that of Montoro, but total anthocyanins in Montoro were 30-fold higher than that of Tropea [40]; however quercetin and catechins were with antiatherosclerotic effect [41]. Onion peel extract is an important ingredient for nutraceuticals and functional foods based on p-coumaric acid, vanillic acid, epicatechin, and morin [42].

2.3. Chinese Chive. Chinese chive (Allium tuberosum) is an important source of dietary phytochemicals with proven antioxidant properties, such as organosulfur compounds, flavonoids, and saponins. 47 Compounds of the essential oil in wild Chinese chive were identified, which included 28 sulfur-containing compounds, 4 aldehydes, 3 alcohols, 3 ketones, and hydrocarbons [43]. Allium tuberosum Rottler 
TABLE 1: Functional components for preventing chronic disease in garlic, onion, and Chinese chive.

\begin{tabular}{|c|c|c|c|}
\hline Chronic disease & Alliums & Functional components & Ref. \\
\hline \multirow[t]{3}{*}{ Anticancer } & Garlic & $\begin{array}{l}\text { Allicin[diallyl thiosulfinate]; S-allylmercaptocysteine; } \\
\text { S-propargyl-L-cysteine; } S \text {-benzyl-cysteine; polysulfanes; } \\
\text { diallylpolysulfides; allyl mercaptan; Z-ajoene; }\end{array}$ & {$[50-62]$} \\
\hline & Onion & onionin A; fisetin; diosgenin; quercetin & {$[63-66]$} \\
\hline & Chinese chive & thiosulfinates; tuberoside M & {$[67,68]$} \\
\hline \multirow{3}{*}{$\begin{array}{l}\text { Preventive cardiovascular } \\
\text { diseases }\end{array}$} & Garlic & Allicin, allyl sulfides; flavonoids; polysulfides; & {$[69-71]$} \\
\hline & Onion & quercetin; flavonoids; furostanol saponins; thiosulfinates & {$[72-75]$} \\
\hline & Chinese chive & Glycosides; amino-styrene-acrylic acids & [76] \\
\hline \multirow{2}{*}{ Preventive heart diseases } & Garlic & S-Propargyl-cysteine; allicin; garlic oil; polysulfides & {$[27,77,78]$} \\
\hline & Onion & Quercetin & [79] \\
\hline \multirow{2}{*}{ Anti-inflammation } & Garlic & $S$-Propargyl-cysteine; allicin; diallyl trisulfide & {$[27,80-85]$} \\
\hline & Onion & Quercetin-3-O-glucoside & [86] \\
\hline \multirow{2}{*}{ Antiobesity } & Garlic & Diallyl disulfide; $S$-methyl L-cysteine & {$[87,88]$} \\
\hline & Onion & S-Methyl L-cysteine; quercetin & {$[88-91]$} \\
\hline \multirow[t]{2}{*}{ Antidiabetes } & Garlic & $\begin{array}{l}\text { S-Methyl L-cysteine; } S \text {-allylcysteine; diallyl disulphide; } \\
\text { S-Allyl-mercapto-captopril }\end{array}$ & {$[88,92-94]$} \\
\hline & Onion & S-Methylcysteine; flavonoids & {$[95]$} \\
\hline \multirow[t]{2}{*}{ Neuroprotective effects } & Garlic & $\begin{array}{l}\mathrm{N} \text { - } \alpha \text {-(1-Deoxy-D-fructos-1-yl)-L-arginine; } S \text {-methylcysteine; allicin; } \\
S \text {-allylcysteine; } S \text {-allyl-L-cysteine; diallyl disulfide; diallyl trisulfide; } \\
\text { Z-ajoene }\end{array}$ & {$[22,27,96-99]$} \\
\hline & Onion & Flavonoids; quercetin & {$[100,101]$} \\
\hline \multirow{2}{*}{ Immunological effects } & Garlic & Allyl methyl disulfide & {$[53]$} \\
\hline & Onion & Onion extracts & {$[102]$} \\
\hline \multirow[t]{2}{*}{ Antimicrobial activities } & Garlic & $\begin{array}{l}\text { Allicin; thiosulfinates; diallyl monosulfide; diallyl disulfide; diallyl } \\
\text { trisulfide; diallyl tetrasulfide; ajoene }\end{array}$ & {$[20,103-106]$} \\
\hline & Onion & Saponins; Ace-AMP1 & {$[36,107,108]$} \\
\hline
\end{tabular}

has two new phenylpropane glycosides and four known flavonoids (kaempferol 3-O- $\beta$-sophoroside; 3-O- $\beta$-D-(2-Oferuloyl)-glucosyl-7,4-di-O- $\beta$-D-glucosyl-kaempferol; 3-O$\beta$-sophorosyl-7-O- $\beta$-D-(2-O-feruloyl) glucosyl-kaempferol; and kaempferol 3,4'-di-O- $\beta$-D-glucoside) [44]. The major components and percentage of volatile oil were $39.31 \%$ diallyl disulphide, $32.76 \%$ disulfide-methyl-2-propenyl, and $12.16 \%$ trisulfide-di-2-propenyl; Chinese chive volatile oil showed extensively potential ability for neotype antibacterials and food preservative [45]. The volatiles of Chinese chive contained allyl methyl sulfide and diallyl disulfide [46]. Allium tuberosum is an important functional foods with antitumor, anti-inflammation, nerve protection, and antioxidant activity; nine compounds which were isolated from the roots were identified as 4,8-dihydroxyacetophenone-8-O-ferulate; 4,8-dihydroxyacetophenone; 3,4,5-trimethoxybenzoic acid; 3,4,5-trimethoxycinnamic acid; buddlenol D; $E$-1,6,11-triene4,5,9-trithiadodeca-9,9-dioxide; tianshic acid; daucosterol; and linoleic acid [47]. A new phenylpropanoid glucoside tuberosinine D and a chain compound (Z)-11R,12S,13Strihydroxy-9-octadecenoate were isolated from the roots of Allium tuberosum [48]. Six spirostanol saponins from the roots of Allium tuberosum, among them are 25(S)-Schidigerasaponin D5, shatavarin IV, and new saponin 2, showed antibacterial activities against Bacillus subtilis and Escherichia coli $[49]$.

\section{Chronic Disease Prevention of Allium Genus}

In Table 1 are summarized the studies reporting the functional components for preventing chronic diseases in Alliums genus.

3.1. Functional Components and Anticancer of the Allium Genus. Functional components in garlic of anticancer effect included allicin [diallyl thiosulfinate], $S$-allylmercaptocysteine, $S$-propargyl-L-cysteine, $S$-benzyl-cysteine, polysulfanes, diallylpolysulfides, allyl mercaptan, and Zajoene; nevertheless, major functional components in onion of anticancer effect contained onionin A, fisetin, diosgenin, and quercetin. Moreover, major functional components in Chinese chive of anticancer effect were thiosulfinates and tuberoside M (see Table 1). These data showed that functional components and molecular mechanism for anticancer effect had significant difference among garlic and onion as well as Chinese chive, but it is necessary to conduct future research on similar functional components and molecular mechanism for anticancer effect in Allium genus.

3.1.1. Garlic. Allicin from garlic can inhibit the development and metastasis of colorectal cancer, based on improving the 
immune function and inhibiting tumor vessel formation as well as the expression of surviving gene, so as to promote the apoptosis of cancer cells [50]. Allicin inhibits $\mathrm{H}_{2} \mathrm{O}_{2}$-induced senescence in human umbilical vein endothelial cells through activation of SIRT1 [51]. Allicin can improve pancreatic cancer therapy which would reverse gene silencing and suppress cancer cell growth [52]. Allicin from garlic can inhibit the proliferation and induce the apoptosis of MGC 803 human gastric carcinoma cells, which may be achieved through the enhanced expression of p38 and cleaved caspase 3 [53]. JNK activation and mitochondrial Bax translocation are involved in allicin-induced apoptosis in human ovarian cancer SKOV3 cells [54]; however, allicin and $S$-allylmercaptocysteine as well as $S$-propargyl-L-cysteine were one of the novel remedies which possess lots of human antitumor activities including neuroblastoma, adenocarcinoma, and breast cancer [5557]. Garlic has been used as treatment for benign prostatic hyperplasia [109]. S-benzyl-cysteine in aged garlic extract is a structural analog of $S$-allylcysteine, which activated the mitochondrial-dependent apoptosis through p53 and $\mathrm{Bax} / \mathrm{Bcl}-2$ pathways in human gastric cancer cells [58]. The diallyl trisulfide, diallyl tetrasulfide, diallyl sulfide, and diallyl disulfide from garlic have various anticancer activities such as affecting the gene expression of human colon cancer cells $[59,60]$. The allyl mercaptan with the best histone deacetylase inhibitor from garlic revealed its anticancer mechanisms [61]; however Z-ajoene from garlic can be treated the glioblastoma by targeting its cancer stem cells [62]. Garlic intake is negatively associated with the cancer and cardiovascular disease, based on activation of genes with immunity, apoptosis, and xenobiotic metabolism [110].

3.1.2. Onion. Onionin A from onions is considered useful for the additional treatment of patients with ovarian cancer owing to its suppression of the protumor activation of tumor-associated macrophages and direct cytotoxicity against cancer cells [63]. The flavonoid fisetin (3,7,3,4tetrahydroxyflavone) from onion is a promising agent for cancer treatment [64]. Onion can be used to improve hyperglycemia and insulin resistance in breast cancer in chemotherapy [111]. The quercetin and diosgenin of onion can be used as a good anticancer therapy by small ligand molecules for targeting neuropilin-1 receptor and inhibiting growth of various cancer cells $[65,66]$.

3.1.3. Chinese Chive. The thiosulfinates from Chinese chive inhibited the proliferation and activation of human colon cell by the caspase-independent apoptotic pathways [67]. Tuberoside $\mathrm{M}$ from seeds of Chinese chive has a significant effect for inhibiting the growth of human leukemia cells [68].

\subsection{Functional Components and Preventing Cardiovascular} Diseases of the Alliums Genus. Functional components in garlic of preventing cardiovascular diseases included allicin, allyl sulfides, flavonoids, and polysulfides; nevertheless, major functional components in onion of preventing cardiovascular diseases contained quercetin, flavonoids, furostanol saponins, and thiosulfinates. Moreover, major functional components in Chinese chive of preventing cardiovascular diseases were quercetin, flavonoids, furostanol saponins, and thiosulfinates (see Table 1). These data showed that functional components and molecular mechanism for preventing cardiovascular diseases effect had significant difference between garlic and onion, but it is necessary to conduct future research on similar flavonoids and their molecular mechanism for preventing cardiovascular diseases in Allium genus.

3.2.1. Garlic. Lots of organosulfur compounds (allicin, allyl sulfides) from garlic are responsible for the food function of prevention of cardiovascular diseases (cancer, hypertension, dyslipidemia, obesity, and hyperglycemia) [69]. Garlic can play an important role in preventing atherosclerosis and cardiovascular protection based on risk factor reduction of hypertension and total cholesterol as well as surrogate markers $[112,113]$. The garlic bulbs of " $74-x$ " had the highest phenolic content (total phenolic, flavonoids), which associated with the strongest antioxidant and protection abilities [70]. $\mathrm{H}_{2} \mathrm{~S}$ is a key signaling molecule that induces the relaxation and vasodilation of smooth muscle cell and lowering blood pressure [71]. Daily garlic intake is a predictor of endothelial function for patients with ischemic stroke and preventing atherosclerotic [114].

3.2.2. Onion. The flavonoids and quercetin in onion could be recommended for preventing and treating various cardiovascular diseases by controlling cholesterol level and enhancing antioxidation ability $[72,73]$. The seeds of onion with eight new furostanol saponins can treat diarrhea and promote blood flow of human population for Uygur nationality in China [74]. The thiosulfinates of onion with antiplatelet agents can prevent cardiovascular diseases [75].

3.2.3. Chinese Chive. Chinese chive leaf water-soluble substances (amino-styrene-acrylic acids and their glycosides) have a strong anticoagulant effect, while the butanol extract promotes the coagulation of the blood, in favor of understanding the reasons of traditional Chinese medicine about Allium tuberosum with invigorating the circulation of blood and hemostasis [76].

3.3. Functional Components and Preventing Heart Diseases of the Allium Genus. Functional components in garlic of preventing heart diseases included allicin, $S$-propargyl-cysteine, garlic oil, and polysulfides; nevertheless, major functional components in onion of preventing heart diseases contained quercetin (see Table 1). These data showed that functional components and molecular mechanism for preventing heart diseases had significant difference among garlic and onion, but it is necessary to conduct future research on similar components and their molecular mechanism for preventing cardiovascular diseases in Allium genus.

3.3.1. Garlic. Allicin from garlic may exhibit antimyocardial fibrosis effect and the mechanism related to TGF $\beta /$ Smads signal transduction [77]. S-propargyl-cysteine has shown cardioprotection in ischemic heart disease [27]. Garlic-derived 
polysulfides may be useful in the treatment of myocardial ischemic disease [78]. Garlic exhibits cardioprotective properties against cardiotoxicity, arrhythmia, hypertrophy, ischemia-reperfusion injury, cardiac and mitochondrial dysfunction, and myocardial infarction $[115,116]$.

3.3.2. Onion. The quercetin with cardioprotection from onion skin reduces ambulatory blood pressure in hypertension patients [79]. Onion extract $(10 \mathrm{~g} / \mathrm{kg})$ decreased the infarct size and cell death of heart [117].

\subsection{Functional Components and Anti-Inflammation of the} Alliums Genus. Functional components in garlic of antiinflammation included allicin, $S$-propargyl-cysteine, and diallyl trisulfide; nevertheless, major functional components in onion of anti-inflammation contained quercetin-3-Oglucoside (see Table 1). These data showed that functional components and molecular mechanism for antiinflammation had significant difference between garlic and onion, but it is necessary to conduct future research on similar components and their molecular mechanism for antiinflammation in Allium genus.

3.4.1. Garlic. The garlic and onion showed the anti-inflammatory and antioxidant effects [118]. Allicin from garlic displays a significant protective effect against EA.hy926 endothelial cell injury induced by PM2.5 and its mechanism may be related to the attenuations of inflammation and oxidative stress via the inhibition of ERK1/2 pathway [80]. Allicin from garlic may be useful in reducing oxidative stress, inflammation, vascular dysfunction, and the aortic pathology [81, 82]. S-propargyl-cysteine has shown antiinflammation in acute pancreatitis [27]. Diallyl trisulfide in five organosulfur compounds from garlic is not only a highly promising therapeutic candidate for treating inflammationrelated neurodegenerative diseases [83], but also has varied potential therapeutic activities, especially periodontal inflammation [84], which revealed anti-inflammatory effect by downregulating AKT1/TGF- $\beta$-activated kinase-mediated $\mathrm{NF} \kappa \mathrm{B}$ and MAPK signaling pathways [85].

3.4.2. Onion. Onion stalk extract can be used as reducing atherosclerosis and regulating inflammatory response [119]. Eicosapentaenoic acid combined quercetin-3-O-glucoside from onion had significant anti-inflammation and hypolipidemic effects, which can be used as the treatment of obesityrelated diseases [86].

3.5. Functional Components and Antiobesity of the Allium Genus. Functional components in garlic of antiobesity included diallyl disulfide and $S$-methyl L-cysteine; nevertheless, major functional components in onion of antiobesity contained S-methyl L-cysteine and quercetin (see Table 1). These data showed that functional components and molecular mechanism for antiobesity had similar organosulfur compounds between garlic and onion.
3.5.1. Garlic. Garlic can reduce body weight and fat mass among subjects [120]; meanwhile $20 \mathrm{mg} / \mathrm{kg}$ diallyl disulfide was effective in preventing nonalcoholic fatty liver disease [87]. Garlic compared with placebo can not only effectively reduce serum lipids and body mass index in elderly hyperlipidemic patients [121], but also minimised the high-fatdiet-induced fatty liver changes in rats [122]. Administration of garlic plus lemon juice resulted in an improvement in lipid levels, fibrinogen, and blood pressure of patients with hyperlipidemia [123]. S-methyl L-cysteine from garlic and onion found to be effective in improving the high fructose induced hyperglycemia and dyslipidemia [88].

3.5.2. Onion. Onion consumption combined with healthy diet can be effective in nonalcoholic fatty liver disease management [124]. Quercetin in onion peel could not only ameliorate the flow-mediated dilation and circulating endothelial progenitor cells, antiobesity by suppressing preadipocyte differentiation and inhibiting adipogenesis, and genes regulating intracellular lipolysis, but also has anticholesterol, antithrombotic, and insulin-sensitizing properties [89-91].

3.6. Functional Components and Antidiabetes of the Alliums Genus. Functional components in garlic of antidiabetes included $S$-methyl L-cysteine, $S$-allyl cysteine, diallyl disulphide, and $S$-allyl-mercapto-captopril; nevertheless, major functional components in onion of antidiabetes contained S-methylcysteine and flavonoids (see Table 1). These data showed that functional components and molecular mechanism for antidiabetes had similar organosulfur compounds between garlic and onion.

3.6.1. Garlic. S-methyl L-cysteine from garlic and onion could treat and manage the diabetes [88]; however $S$ allylcysteine might be stimulating the synthesis of insulin through circulating thyroid hormones [92]. Diallyl disulphide of garlic oil has the hypolipidemic effect and reducing the morbidity in diabetes [93]. The S-allyl-mercaptocaptopril for a promising antidiabetic and cardiovascular protective agent integrates the antihypertensive feature between allicin and captopril [94]. Garlic plays an important role of improving metabolic syndrome containing abdominal obesity, hypertension, dyslipidemia, and hyperglycemia disorders [125], which prevents obesity by the downregulation of gene expression patterns [126].

3.6.2. Onion. S-methylcysteine and flavonoids of onion can decrease the levels of blood glucose, serum lipids, oxidative stress, and lipid peroxidation, meanwhile increasing insulin secretion and antioxidant enzyme activity [95]. The ethanolic extract of onion can control diabetes by the phosphatidylinositol-4,5-bisphosphate 3-kinase/Akt dependent pathway [127].

3.7. Functional Components and Neuroprotective Effects of the Allium Genus. Functional components in garlic of neuroprotective effects included allicin, $S$-methylcysteine, $S$-allyl cysteine, $S$-allyl-L-cysteine, diallyl disulfide, diallyl 
trisulfide, N- $\alpha$-(1-deoxy-D-fructose-1-yl)-L-arginine, and Zajoene; nevertheless, major functional components in onion of neuroprotective effects contained flavonoids and quercetin (see Table 1). These data showed that functional components and molecular mechanism for neuroprotective effects had significant difference among garlic and onion, but it is necessary to conduct future research on similar components and their molecular mechanism for neuroprotective effects in Allium genus.

3.7.1. Garlic. Allicin from garlic can be used as a neuroprotective strategy for ischemic stroke [96]; however S-propargylcysteine and $S$-methyl cysteine were the effective neuroprotective agents $[27,128]$. $S$-allyl-L-cysteine from garlic against neuronal cell death of endoplasmic reticulum stress is inhibiting calpain by interaction with its $\mathrm{Ca}^{2+}$-binding site [129]; meanwhile diallyl disulfide possess the hippocampal neurogenesis and neurocognitive functions through modulating ERK and BDNF-CREB signaling [97]. Diallyl trisulfide in garlic oil has lots of neuroprotective effects in transgenic mice [98]. Aged garlic extract and its N- $\alpha$-(1-deoxy-D-fructos-1yl)-L-arginine could attenuate neuroinflammatory and promote resilience in lipopolysaccharide-activated cells [130]. Zajoene from garlic oil and aged garlic extract could promote neuroprotective effects by reducing lipid peroxidation and antioxidant or anti-inflammatory activities $[99,131]$.

3.7.2. Onion. Flavonoids extracted from onion could ameliorate symptoms of intracerebral hemorrhage by inhibiting activation of microglia and relieve proinflammatory factors of hematoma [100]; however quercetin could protect brain cells against oxidative stress for Alzheimer's disease and neurodegenerative disorders [101]. The onion extract could prevent the blood-brain barrier during brain ischemia [132].

3.8. Functional Components and Immunological Effects of the Alliums Genus. Functional components of immunological effects included allyl methyl disulfide and so on. Allyl methyl disulfide from fresh garlic can treat the immunological disorders, such as ulcerative colitis, Crohn's disease, and intestinal inflammation [53]. Lipid garlic extract as an immunotherapy has better cure rates for the recalcitrant multiple common warts [133]. Fresh aqueous garlic and onion extracts play an important role in enhancing immune function [102].

\subsection{Functional Components and Antimicrobial Activities} of the Allium Genus. Functional components in garlic of antimicrobial activities included allicin, thiosulfinates, diallyl monosulfide, diallyl disulfide, diallyl trisulfide, diallyl tetrasulfide, and ajoene; nevertheless, major functional components in onion of antimicrobial activities contained saponins and Ace-AMP1 (see Table 1). These data showed that functional components and molecular mechanism for antimicrobial activities had significant difference among garlic and onion, but it is necessary to conduct future research on similar components and their molecular mechanism for neuroprotective effects in Allium genus.
The components of antimicrobial activities (bacteria, fungi, viruses, and parasites) of garlic are allicin, thiosulfinates, and others $[103,104]$. Antimicrobial activity of allicin was a thiol reagent [105]; however garlic oils showed a good antimicrobial activity against Staphylococcus aureus, Pseudomonas aeruginosa, and Escherichia coli, based on diallyl monosulfide, diallyl disulfide, diallyl trisulfide, and diallyl tetrasulfide [106]. Allicin and ajoene as well as oil from garlic showed significant antimycobacterial and antibacterial activity [20]. Garlic oil has the anti-influenza virus activities in mice [134].

The chemical structure of five new saponins compounds (persicosides $\mathrm{A}$ and $\mathrm{B}$, persicosides $\mathrm{C} 1 / \mathrm{C} 2$ and $\mathrm{D} 1 / \mathrm{D} 2$, and persicoside E) from Persian leek as well as three saponins (ceposides $A, B$, and $C$ ) from the bulbs of white onion were identified, while persicosides (A, B) and ceposides (A, B, and C) showed the higher antifungal activity $[36,107]$. Ace-AMP1 is a potent antifungal peptide found in onion seeds and could be used as an effective fungicide [108].

3.10. Functional Components and Other Effects of the Alliums Genus. $\gamma$-Glutamyl-S-allyl-cysteine peptide of fresh garlic involves the radical scavenging and metal-chelating capacities [135]. Garlic + onion can remarkably decrease in liver steatosis, serum liver enzymes, oxidative markers, and lipid peroxidation than that of vegetables alone [136]. Garlic saponins can protect dPC12 cells from hypoxia damage [137].

\section{Major Mechanisms and Structural Activity of Alliums Compounds for Preventive Chronic Disease}

4.1. Organopolysulfides Mechanism and Its Structural Activity. Major mechanisms of alliums organopolysulfides for preventive chronic disease include anticancer, preventive cardiovascular and heart diseases, anti-inflammation, antiobesity, antidiabetes, antimicrobial activities, and neuroprotective and immunological effects (Figure 1). Hydrogen sulfide $\left(\mathrm{H}_{2} \mathrm{~S}\right)$ is a gaseous signaling molecule; however, the polysulfides as $\mathrm{H}_{2} \mathrm{~S}$ donors have established the relationship between structure and health promotion activity [138]. Preventive mechanism for some chronic diseases of garlic and onion is an active mechanism of many therapeutic effects such as cardiovascular disorders, obesity, metabolic syndrome, gastric ulcer, and even cancer by modulating cytokine secretion with immunomodulation and anti-inflammatory effects for sulfur-containing compounds [139]. Anticancer mechanism of garlic and onion is the induction of apoptosis for cancer cells by sulfur-containing compounds [140]. The mechanisms of polysulfides in cardioprotection are as follows: $\mathrm{H}_{2} \mathrm{~S}$ releasing, radical scavenging, and gene regulation with enzyme pathways [138]. ZYZ-803 with therapeutic cardiovascular diseases is a $\mathrm{H}_{2} \mathrm{~S}-\mathrm{NO}$ conjugated donor developed by $S$-propylL-cysteine and furoxan; based on this it can regulate vascular tone through cGMP pathway [141]; $\mathrm{H}_{2} \mathrm{~S}$ is biosynthesized by three enzymes from L-cysteine and homocysteine; NO is generated endogenously from L-arginine by the action of various isoforms of NOS; two gases have been transpired 


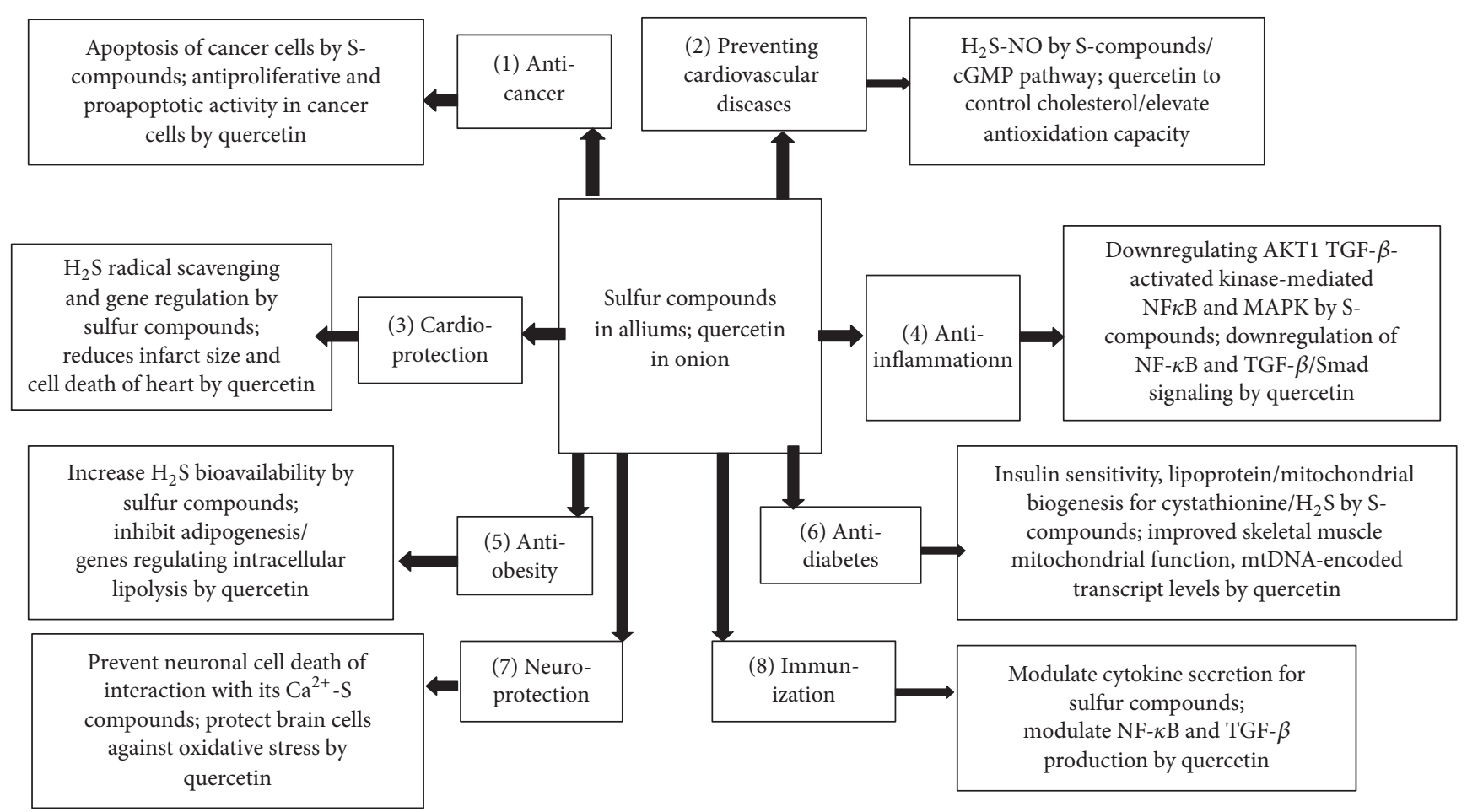

Figure 1: Possible mechanisms of functional components in allium for preventive chronic disease.

as the key and independent regulators of cardiovascular, nervous, gastrointestinal, respiratory, and immune systems [142]. Obesity in mice reduced the $\mathrm{H}_{2} \mathrm{~S}$ bioavailability; the depletion of macrophage $\mathrm{H}_{2} \mathrm{~S}$ increases the store-operated $\mathrm{Ca}^{2+}$ entry through disinhibition of Orai 3 and promotes the production of proinflammatory cytokines [143]. Cystathionine $\gamma$-lyase-derived $\mathrm{H}_{2} \mathrm{~S}$ affects lipoprotein synthesis, insulin sensitivity, and mitochondrial biogenesis, in which tissuespecific regulation pathway might be a promising therapeutic target of diabetes and other metabolic syndromes [144]. The ameliorative action of organopolysulfides in garlic on the elevated blood pressure and renal clearance functions in diabetes may be mediated through attenuating modulations in plasma and kidney angiotensin I converting enzyme type1 and angiotensin II concentrations; thiosulfinate in garlic is a promising agent for the management of postprandial hyperglycemia $[145,146]$.

\subsection{Quercetin Mechanism and Its Structural Activity. Major} mechanisms of alliums compounds especially quercetin for preventive chronic disease include anticancer, preventive cardiovascular and heart diseases, anti-inflammation, antiobesity, antidiabetes, antimicrobial activities, and neuroprotective and immunological effects (Figure 1). Quercetin in onion is not only a bioflavonoid with antiproliferative and proapoptotic activity in many cancer cells [147] but also has neuroprotective effects by stimulating cellular defenses against oxidative stress [148] and has combating various cardiovascular diseases by suppressing cholesterol level and elevate total antioxidation capacity [72]. Quercetin in onions increases insulin sensitivity and adiposity and improves glucose tolerance, based on improved skeletal muscle mitochondrial number and function, and mtDNA-encoded transcript levels [149]. Daily quercetin supplementation is associated with antioxidative and anti-inflammatory potential and downregulation of NF- $\kappa \mathrm{B}$ and TGF- $\beta /$ Smad signaling, probably via interference with TLR signaling [150]. Onions extract and quercetin with downregulated NF- $\kappa \mathrm{B}$ pathway can inhibit RANKL/Porphyromonas gingivalis LPS-induced osteoclastogenesis under inflammatory conditions via attenuation of $\mathrm{NF}-\kappa \mathrm{B}$ activation [151]. Orally administered quercetin has antihypertensive effect and is responsible for vasorelaxant activity [152]. The protective mechanisms of onions extract and its quercetin against BSO-induced oxidative stress in neuronal cells associate with the inactivation of PKC- $\varepsilon$ induced by phosphorylating ERK1/2 [153]. Quercetin has an effective therapeutic strategy for patients with liver damage and fibrosis of immune response, based on association with its ability to modulate NF- $\kappa \mathrm{B}$ and TGF- $\beta$ production [154].

\section{Conclusion Remarks and Future Perspectives}

The data summarized in the current review point out that major mechanism and many functional components derived from Allium genus, especially garlic and onion, exert potent preventing chronic diseases. Although functional components in Alliums for preventing and treating chronic diseases seem a complicated task, the development of functional foods may still open new venues for therapeutic interventions. 
Regular consumption of such functional foods for Allium may become a successful and safe strategy to treat chronic disease conditions. These data support that Allium genus especially garlic and onion is rich in organosulfur compounds and quercetin, which are known to play a pivotal role in many chronic diseases.

This review provides useful information that will guide future research, which will provide strategies for efficient, organosulfur-based prevention, or treatment, of chronic diseases. Further efforts are needed to resolve several remaining hurdles, such as a better understanding of the interconnection between functional components and preventing chronic diseases in clinical trials. Further studies are necessary to unravel the key compounds for preventing and treating chronic disease of other Allium genus except garlic and onion, as these compounds present various mechanistic actions and their clinical applications need to be tested. This review may be used as a starting point for novel nutraceuticals, functional foods, or complementary and alternative drugs to maintain or improve the chronic diseases.

\section{Competing Interests}

The authors declare that there is no conflict of interests.

\section{Acknowledgments}

This review was supported by the Science and Technology to Benefit the People from Yunnan Provincial Scientific and Technology Department (2014RA060) and China Agriculture Research System (CARS-05).

\section{References}

[1] Y.-W. Zeng, J. Du, X.-Y. Pu et al., “Coevolution between human's anticancer activities and functional foods from crop origin center in the world," Asian Pacific Journal of Cancer Prevention, vol. 16, no. 6, pp. 2119-2128, 2015.

[2] I. D. Nwachukwu, A. J. Slusarenko, and M. C. H. Gruhlke, "Sulfur and sulfur compounds in plant defence," Natural Product Communications, vol. 7, no. 3, pp. 395-400, 2012.

[3] M. C. H. Gruhlke and A. J. Slusarenko, "The biology of reactive sulfur species (RSS)," Plant Physiology and Biochemistry, vol. 59, pp. 98-107, 2012.

[4] J. O. Fuss, C.-L. Tsai, J. P. Ishida, and J. A. Tainer, "Emerging critical roles of Fe-S clusters in DNA replication and repair," Biochimica et Biophysica Acta, vol. 1853, no. 6, pp. 1253-1271, 2015.

[5] D. E. Bloom, E. T. Cafiero, E. Jané-Llopis et al., The Global Economic Burden of Noncommunicable Diseases, World Economic Forum, Geneva, Switzerland, 2011, http://www.weorum.org/ EconomicsONCD.

[6] Y. W. Zeng, D. Sun, J. Du et al., "Identification of QTLs for resistant starch and total alkaloid content in brown and polished rice," Genetics and Molecular Research, vol. 15, no. 3, 2016.

[7] D.-C. Tsai, M.-C. Liu, Y.-R. Lin, M.-F. Huang, and S.-S. Liang, "A novel reductive amination method with isotopic formaldehydes for the preparation of internal standard and standards for determining organosulfur compounds in garlic," Food Chemistry, vol. 197, pp. 692-698, 2016.
[8] C.-H. Huang, F.-Y. Hsu, Y.-H. Wu et al., "Analysis of lifespanpromoting effect of garlic extract by an integrated metaboloproteomics approach," Journal of Nutritional Biochemistry, vol. 26, no. 8, pp. 808-817, 2015.

[9] J. M. Bradley, C. L. Organ, and D. J. Lefer, "Garlic-derived organic polysulfides and myocardial protection," Journal of Nutrition, vol. 146, no. 2, pp. 403-409, 2016.

[10] Y. Zhou, W. Zhuang, W. Hu, G. J. Liu, T. X. Wu, and X. T. Wu, "Consumption of large amounts of Allium vegetables reduces risk for gastric cancer in a meta-analysis," Gastroenterology, vol. 141, no. 1, pp. 80-89, 2011.

[11] C. Galeone, F. Turati, Z.-F. Zhang et al., "Relation of allium vegetables intake with head and neck cancers: evidence from the INHANCE consortium," Molecular Nutrition \& Food Research, vol. 59, no. 9, pp. 1641-1650, 2015.

[12] D. Mnayer, A.-S. Fabiano-Tixier, E. Petitcolas et al., "Chemical composition, antibacterial and antioxidant activities of six essentials oils from the Alliaceae family," Molecules, vol. 19, no. 12, pp. 20034-20053, 2014.

[13] H.-F. Chiu, Y.-C. Shen, T.-Y. Huang, K. Venkatakrishnan, and C.-K. Wang, "Cardioprotective efficacy of red wine extract of onion in healthy hypercholesterolemic subjects," Phytotherapy Research, vol. 30, no. 3, pp. 380-385, 2016.

[14] J. Sharifi-Rad, D. Mnayer, G. Tabanelli et al., "Plants of the genus Allium as antibacterial agents: from tradition to pharmacy," Cellular and Molecular Biology, vol. 62, no. 9, pp. 57-68, 2016.

[15] Q. Q. Li, "Study on edible plant resources species of Allium L. in China," Journal of Anhui Agricultural Sciences, vol. 43, no. 13, pp. 7-11, 2015.

[16] S.-M. Zhou, L.-M. Chen, S.-Q. Liu, X.-F. Wang, and X.-D. Sun, "De novo assembly and annotation of the Chinese chive (Allium tuberosum Rottler ex Spr.) transcriptome using the Illumina platform," PLoS ONE, vol. 10, no. 7, Article ID e0133312, 2015.

[17] C. I. Abuajah, A. C. Ogbonna, and C. M. Osuji, "Functional components and medicinal properties of food: a review," Journal of Food Science and Technology, vol. 52, no. 5, pp. 2522-2529, 2015.

[18] N. Yoshimoto, M. Onuma, S. Mizuno et al., "Identification of a flavin-containing S-oxygenating monooxygenase involved in alliin biosynthesis in garlic," Plant Journal, vol. 83, no. 6, pp. 941951, 2015.

[19] R. Kubec, P. Urajová, O. Lacina, J. Hajšlová, M. Kuzma, and J. Zápal, "Allium discoloration: color compounds formed during pinking of onion and leek," Journal of Agricultural and Food Chemistry, vol. 63, no. 46, pp. 10192-10199, 2015.

[20] V. Viswanathan, A. G. Phadatare, and A. Mukne, "Antimycobacterial and antibacterial activity of Allium sativum bulbs," Indian Journal of Pharmaceutical Sciences, vol. 76, no. 3, pp. 256-261, 2014.

[21] J. Borlinghaus, F. Albrecht, M. C. H. Gruhlke, I. D. Nwachukwu, and A. J. Slusarenko, "Allicin: chemistry and biological properties," Molecules, vol. 19, no. 8, pp. 12591-12618, 2014.

[22] A. L. Colín-González, S. F. Ali, I. Túnez, and A. Santamaría, "On the antioxidant, neuroprotective and anti-inflammatory properties of S-allyl cysteine: an update," Neurochemistry International, vol. 89, pp. 83-91, 2015.

[23] S. Kodai, S. Takemura, S. Kubo, H. Azuma, and Y. Minamiyama, "Therapeutic administration of an ingredient of agedg-arlic extracts, S-allyl cysteine resolves liver fibrosis established by carbon tetrachloride in rats," Journal of Clinical Biochemistry and Nutrition, vol. 56, no. 3, pp. 179-185, 2015. 
[24] Y. Liu, J. Yan, X. Han, and W. Hu, "Garlic-derived compound S-allylmercaptocysteine (SAMC) is active against anaplastic thyroid cancer cell line 8305C (HPACC)," Technology and Health Care, vol. 23, supplement 1, pp. S89-S93, 2015.

[25] S. M. Saud, W. Li, Z. Gray et al., "Diallyl disulfide (DADS), a constituent of garlic, inactivates NF- $\kappa \mathrm{B}$ and prevents colitisinduced colorectal cancer by inhibiting GSK-3 $\beta$," Cancer Prevention Research, vol. 9, no. 7, pp. 607-615, 2016.

[26] P. Dasgupta and S. S. Bandyopadhyay, "Role of Di-allyl disulfide, a garlic component in NF- $\kappa$ B mediated transient G2-M phase arrest and apoptosis in human leukemic cell-lines," Nutrition and Cancer, vol. 65, no. 4, pp. 611-622, 2013.

[27] Y. D. Wen and Y. Z. Zhu, "The Pharmacological effects of Spropargyl-cysteine, a novel endogenous $\mathrm{H}_{2} \mathrm{~S}$ - producing compound," Handbook of Experimental Pharmacology, vol. 230, pp. 325-336, 2015.

[28] S. R. Kim, Y. R. Jung, H. J. An et al., "Anti-wrinkle and anti-inflammatory effects of active garlic components and the inhibition of MMPs via NF- $\kappa$ B signaling," PLoS ONE, vol. 8, no. 9, Article ID e73877, 12 pages, 2013.

[29] T.-C. Hsia and M.-C. Yin, "S-ethyl cysteine and S-methyl cysteine protect human bronchial epithelial cells against hydrogen peroxide induced injury," Journal of Food Science, vol. 80, no. 9, pp. H2094-H2101, 2015.

[30] B. L. Song, W. Zhang, R. M. Shi, Q. Huang, X. X. Li, and J. Chen, "Study on the comparison and correlation of chemical constituents of garlic," Chinese Journal of Pharmaceutical Analysis, vol. 36, no. 4, pp. 727-732, 2016.

[31] Y. B. Ning and L. J. Chen, "Extraction and hpoglycemic of black garlic allicin," Food Science and Technology, vol. 41, no. 1, pp. 185189, 2016.

[32] H. J. Lee, H. J. Suh, S. H. Han, J. Hong, and H.-S. Choi, "Optimization of extraction of cycloalliin from garlic (Allium sativum L.) by using principal components analysis," Preventive Nutrition and Food Science, vol. 21, no. 2, pp. 138-146, 2016.

[33] S. K. Lee, Y. J. Park, M. J. Ko et al., "A novel natural compound from garlic (Allium sativum L.) with therapeutic effects against experimental polymicrobial sepsis," Biochemical and Biophysical Research Communications, vol. 464, no. 3, pp. 774-779, 2015.

[34] Y. Wang, T. Zou, M. Xiang et al., "Purification and characterization of a soluble glycoprotein from garlic (Allium sativum) and its in vitro bioactivity," Preparative Biochemistry \& Biotechnology, vol. 46, no. 7, pp. 709-716, 2016.

[35] P. A. Tuan, J. K. Kim, H. H. Kim, S. Y. Lee, N. I. Park, and S. U. Park, "Carotenoid accumulation and characterization of cDNAs encoding phytoene synthase and phytoene desaturase in garlic (Allium sativum)," Journal of Agricultural and Food Chemistry, vol. 59, no. 10, pp. 5412-5417, 2011.

[36] V. Lanzotti, E. Barile, V. Antignani, G. Bonanomi, and F. Scala, "Antifungal saponins from bulbs of garlic, Allium sativum L. var. Voghiera," Phytochemistry, vol. 78, pp. 126-134, 2012.

[37] Y. B. Ning, F. F. Wang, Z. Q. Du, and M. J. Chen, "GC-MS detection for volatile substances of solid state fermentation black onion," Food Research and Development, vol. 35, no. 3, pp. 93-96, 2014.

[38] X. J. Sun, H. D. Xu, and L. F. Mi, "Analysis of volatile compounds from fresh and dried Allium cepa L," Food Science, vol. 33, no. 22, pp. 290-293, 2012.

[39] S. Kook, G.-H. Kim, and K. Choi, "The antidiabetic effect of onion and garlic in experimental diabetic rats: meta-analysis," Journal of Medicinal Food, vol. 12, no. 3, pp. 552-560, 2009.
[40] I. Tedesco, V. Carbone, C. Spagnuolo, P. Minasi, and G. L. Russo, "Identification and quantification of flavonoids from two southern Italian cultivars of Allium cepa L., Tropea (Red Onion) and Montoro (Copper Onion), and their capacity to protect human erythrocytes from oxidative stress," Journal of Agricultural and Food Chemistry, vol. 63, no. 21, pp. 5229-5238, 2015.

[41] N. Jaiswal and S. I. Rizvi, "Onion extract (Allium cepa L.), quercetin and catechin up-regulate paraoxonase 1 activity with concomitant protection against low-density lipoprotein oxidation in male Wistar rats subjected to oxidative stress," Journal of the Science of Food and Agriculture, vol. 94, no. 13, pp. 27522757, 2014.

[42] J. Kim, J. Kim, and E. Park, "Cytotoxic and anti-inflammatory effects of onion peel extract on lipopolysac-charide stimulated human colon carcinoma cells," Food and Chemical Toxicology, vol. 62, pp. 199-204, 2013.

[43] M. Y. Yang, F. P. Zheng, Y. Duan, and J. C. Xie, "Analysis of volatiles in wild Chinese chive flowers by solvent extraction/solvent-assisted flavor evaporation coupled with gas chromatography-mass spectrometry," Food Science, vol. 32, no. 2, pp. 211-216, 2011.

[44] S. H. Han, W. S. Suh, K. J. Park, K. H. Kim, and K. R. Lee, "Two new phenylpropane glycosides from Allium tuberosum Rottler," Archives of Pharmacal Research, vol. 38, no. 7, pp. 1312-1316, 2015.

[45] X. Wang, R. Wu, L. Zhang, L. Liu, H. W. Guan, and P. Luo, "GC-MS analysis of chemical compositions and antimicrobial activity of volative oil from Allium tuberosun against common pathogenic bacteria," Chinese Veterinary Science, vol. 42, no. 2, pp. 201-204, 2012.

[46] C.-Y. Zhang, M.-Z. Si, L. Li, and D.-Q. Zhang, "Research on volatiles of rakkyo (Allium Chinense G. Don) and Chinese chive (Allium Tuberosum rottl. ex sprengel) based on headspace and the molecular recognition of SERS," Spectroscopy and Spectral Analysis, vol. 35, no. 2, pp. 394-398, 2015.

[47] Y.-C. Ma, J. Yu, J.-P. Wang, L. Cai, and Z.-T. Ding, "Chemical constituents of the roots of Allium tuberosum," Chinese Pharmaceutical Journal, vol. 51, no. 12, pp. 972-975, 2016.

[48] Y.-S. Fang, S.-X. Liu, Y.-C. Ma, J.-W. Dong, L. Cai, and Z.-T. Ding, "A new phenylpropanoid glucoside and a chain compound from the roots of Allium tuberosum," Natural Product Research, vol. 31, no. 1, pp. 70-76, 2017.

[49] Y.-S. Fang, L. Cai, Y. Li, J.-P. Wang, H. Xiao, and Z.-T. Ding, "Spirostanol steroids from the roots of Allium tuberosum," Steroids, vol. 100, pp. 1-4, 2015.

[50] X. K. Wang, X. Wang, and J. Huang, "Effects of allicin on experimental colorectal cancer in rats and its mechanism," Product Research \& Development, vol. 28, pp. 943-948, 2016.

[51] H. J. Hu, Y. Q. Pan, X. J. Fan, X. M. Hu, W. W. Zou, and X. L. Lin, "Allicin inhibits $\mathrm{H}_{2} \mathrm{O}_{2}$-induced senescence in human umbilical vein endothelial cells through activation of SIRT1," Chinese Journal of Biochemistry and Molecular Biology, vol. 32, no. 5, pp. 536-543, 2016.

[52] S. V. Chhabria, M. A. Akbarsha, A. P. Li, P. S. Kharkar, and K. B. Desai, "In situ allicin generation using targeted alliinase delivery for inhibition of MIA PaCa-2 cells via epigenetic changes, oxidative stress and cyclin-dependent kinase inhibitor (CDKI) expression," Apoptosis, vol. 20, no. 10, pp. 1388-1409, 2015.

[53] X. Zhang, Y. Zhu, W. Duan, C. Feng, and X. He, "Allicin induces apoptosis of the MGC-803 human gastric carcinoma cell line through the p38 mitogen-activated protein kinase/caspase-3 
signaling pathway," Molecular Medicine Reports, vol. 11, no. 4, pp. 2755-2760, 2015.

[54] L. Xu, J. Yu, D. Zhai et al., "Role of JNK activation and mitochondrial Bax translocation in allicin-induced apoptosis in human ovarian cancer SKOV3 cells," Evidence-Based Complementary and Alternative Medicine, vol. 2014, Article ID 378684, 6 pages, 2014.

[55] J. Zhuang, Y. Li, and Y. Chi, "Role of p38 MAPK activation and mitochondrial cytochrome-c release in allicin-induced apoptosis in SK-N-SH cells," Anti-Cancer Drugs, vol. 27, no. 4, pp. 312-317, 2016.

[56] H. Zhang, K. Wang, G. Lin, and Z. Zhao, "Antitumor mechanisms of S-allyl mercaptocysteine for breast cancer therapy," BMC Complementary and Alternative Medicine, vol. 14, article no. 270, 2014.

[57] W. Wang, J. Cheng, and Y. Zhu, "The JNK signaling pathway is a novel molecular target for S-propargyl- L-cysteine, a naturallyoccurring garlic derivatives: link to its anticancer activity in pancreatic cancer in vitro and in vivo," Current Cancer Drug Targets, vol. 15, no. 7, pp. 613-623, 2015.

[58] H.-J. Sun, L.-Y. Meng, Y. Shen, Y.-Z. Zhu, and H.-R. Liu, "Sbenzyl-cysteine-mediated cell cycle arrest and apoptosis involving activation of mitochondrial-dependent caspase cascade through the p53 pathway in human gastric cancer SGC-7901 cells," Asian Pacific Journal of Cancer Prevention, vol. 14, no. 11, pp. 6379-6384, 2013.

[59] B. Czepukojc, A.-K. Baltes, C. Cerella et al., "Synthetic polysulfane derivatives induce cell cycle arrest and apoptotic cell death in human hematopoietic cancer cells," Food and Chemical Toxicology, vol. 64, pp. 249-257, 2014.

[60] K.-C. Lai, C.-L. Kuo, H.-C. Ho et al., "Diallyl sulfide, diallyl disulfide and diallyl trisulfide affect drug resistant gene expression in colo 205 human colon cancer cells in vitro and in vivo," Phytomedicine, vol. 19, no. 7, pp. 625-630, 2012.

[61] H. Nian, B. Delage, J. T. Pinto, and R. H. Dashwood, "Allyl mercaptan, a garlic-derived organosulfur compound, inhibits histone deacetylase and enhances Sp3 binding on the P21WAF1 promoter," Carcinogenesis, vol. 29, no. 9, pp. 1816-1824, 2008.

[62] Y. Jung, H. Park, H.-Y. Zhao, R. Jeon, J.-H. Ryu, and W.-Y. Kim, "Systemic approaches identify a garlic-derived chemical, Z-ajoene, as a glioblastoma multiforme cancer stem cell-specific targeting agent," Molecules and cells, vol. 37, no. 7, pp. 547-553, 2014.

[63] J. Tsuboki, Y. Fujiwara, H. Horlad et al., "Onionin A inhibits ovarian cancer progression by suppressing cancer cell proliferation and the protumour function of macrophages," Scientific Reports, vol. 6, Article ID 29588, 2016.

[64] T. Rengarajan and N. S. Yaacob, "The flavonoid fisetin as an anticancer agent targeting the growth signaling pathways," European Journal of Pharmacology, vol. 789, pp. 8-16, 2016.

[65] K. Sak, "Site-specific anticancer effects of dietary flavonoid quercetin," Nutrition and Cancer, vol. 66, no. 2, pp. 177-193, 2014.

[66] T. Yasmin, M. T. Ali, S. Haque, and M. Hossain, "Interaction of quercetin of onion with axon guidance protein receptor, NRP-1 plays important role in cancer treatment: an in Silico approach," Interdisciplinary Sciences: Computational Life Sciences, 2015.

[67] J.-H. Lee, H.-S. Yang, K.-W. Park et al., "Mechanisms of thiosulfinates from Allium tuberosum L.-induced apoptosis in HT-29 human colon cancer cells," Toxicology Letters, vol. 188, no. 2, pp. 142-147, 2009.
[68] S.-M. Sang, M.-L. Zou, X.-W. Zhang, A.-N. Lao, and Z.-L. Chen, "Tuberoside M, a new cytotoxic spirostanol saponin from the seeds of Allium tuberosum," Journal of Asian Natural Products Research, vol. 4, no. 1, pp. 69-72, 2002.

[69] T. Seki and T. Hosono, "Prevention of cardiovascular diseases by garlic-derived sulfur compounds," Journal of Nutritional Science and Vitaminology, vol. 61, pp. S83-S85, 2015.

[70] S. Chen, X. Shen, S. Cheng et al., "Evaluation of garlic cultivars for polyphenolic content and antioxidant properties," PLoS ONE, vol. 8, no. 11, Article ID e79730, 12 pages, 2013.

[71] K. Ried and P. Fakler, "Potential of garlic (Allium sativum) in lowering high blood pressure: mechanisms of action and clinical relevance," Integrated Blood Pressure Control, vol. 7, pp. 71-82, 2014.

[72] T.-M. Lu, H.-F. Chiu, Y.-C. Shen, C.-C. Chung, K. Venkatakrishnan, and C.-K. Wang, "Hypocholesterolemic efficacy of quercetin rich onion juice in healthy mild hypercholesterolemic adults: a pilot study," Plant Foods for Human Nutrition, vol. 70, no. 4, pp. 395-400, 2015.

[73] M. Majewska-Wierzbicka and H. Czeczot, "Flavonoids in the prevention and treatment of cardiovascular diseases," Polski Merkuriusz Lekarski, vol. 32, no. 187, pp. 50-54, 2012.

[74] C.-J. Li, L. Yuan, T.-F. Ji, J.-B. Yang, A.-G. Wang, and Y.-L. $\mathrm{Su}$, "Furostanol saponins from the seeds of Allium cepa L.", Fitoterapia, vol. 99, pp. 56-63, 2014.

[75] P. F. Cavagnaro and C. R. Galmarini, "Effect of processing and cooking conditions on onion (Allium cepa L.) induced antiplatelet activity and thiosulfinate content," Journal of Agricultural and Food Chemistry, vol. 60, no. 35, pp. 8731-8737, 2012.

[76] X. Y. Wang, S. S. Ye, and L. Ge, "Analysis of the anticoagulant activity and ingredients of chives," Journal of Chinese Institute of Food Science and Technology, vol. 15, no. 3, pp. 216-222, 2015.

[77] S.-C. Li, L.-N. Ma, J. Chen, and Y.-K. Li, "Effect of allicin on myocardial fibrosis after myocardial infarction in rats and its relationship with TGF $\beta /$ Smads signal transduction," China Journal of Chinese Materia Medica, vol. 41, no. 13, pp. 2517-2521, 2016.

[78] M. Lavu, S. Bhushan, and D. J. Lefer, "Hydrogen sulfidemediated cardioprotection: mechanisms and therapeutic potential," Clinical Science, vol. 120, no. 6, pp. 219-229, 2011.

[79] V. Brüll, C. Burak, B. Stoffel-Wagner et al., "Effects of a quercetin-rich onion skin extract on $24 \mathrm{~h}$ ambulatory blood pressure and endothelial function in overweight-to-obese patients with (pre-)hypertension: a randomised double-blinded placebo-controlled cross-over trial," British Journal of Nutrition, vol. 114, no. 8, pp. 1263-1277, 2015.

[80] Q. Wan, Y. P. Yang, and Z. Y. Liu, "Allicin prevents EA. hy926 endothelial cell injury induced by PM2.5 via inhibiting ERK1/2 pathway," Chinese Pharmacological Bulletin, vol. 32, no. 5, pp. 692-687, 2016.

[81] S. Panyod, W.-K. Wu, C.-T. Ho et al., "Diet supplementation with allicin protects against alcoholic fatty liver disease in mice by improving anti-inflammation and antioxidative functions," Journal of Agricultural and Food Chemistry, vol. 64, no. 38, pp. 7104-7113, 2016.

[82] A. R. El-Sheakh, H. A. Ghoneim, G. M. Suddek, and E. S. Ammar, "Attenuation of oxidative stress, inflammation, and endothelial dysfunction in hypercholesterolemic rabbits by allicin," Canadian Journal of Physiology and Pharmacology, vol. 94, no. 2, pp. 216-224, 2015. 
[83] S.-C. Ho and M.-S. Su, "Evaluating the anti-neuroinflammatory capacity of raw and steamed garlic as well as five organosulfur compounds," Molecules, vol. 19, no. 11, pp. 17697-17714, 2014.

[84] E. Fu, M.-C. Tsai, Y.-T. Chin et al., “The effects of diallyl sulfide upon Porphyromonas gingivalis lipopolysaccharide stimulated proinflammatory cytokine expressions and nuclear factorkappa B activation in human gingival fibroblasts," Journal of Periodontal Research, vol. 50, no. 3, pp. 380-388, 2015.

[85] S. You, E. Nakanishi, H. Kuwata et al., "Inhibitory effects and molecular mechanisms of garlic organosulfur compounds on the production of inflammatory mediators," Molecular Nutrition \& Food Research, vol. 57, no. 11, pp. 2049-2060, 2013.

[86] S. Sekhon-Loodu, Z. Ziaullah, H. P. V. Rupasinghe, Y. Wang, M. Kulka, and F. Shahidi, "Novel quercetin-3-O-glucoside eicosapentaenoic acid ester ameliorates inflammation and hyperlipidemia," Inflammopharmacology, vol. 23, no. 4, pp. 173-185, 2015.

[87] Y.-S. Lai, W.-C. Chen, C.-T. Ho et al., "Garlic essential oil protects against obesity-triggered nonalcoholic fatty liver disease through modulation of lipid metabolism and oxidative stress," Journal of Agricultural and Food Chemistry, vol. 62, no. 25, pp. 5897-5906, 2014.

[88] G. P. Senthilkumar, S. Thomas, K. Sivaraman, P. Sankar, and Z. Bobby, "Study the effect of S-Methyl L-Cysteine on lipid metabolism in an experimental model of diet induced obesity," Journal of Clinical and Diagnostic Research, vol. 7, no. 11, pp. 2449-2451, 2013.

[89] E.-Y. Choi, H. Lee, J. S. Woo et al., "Effect of onion peel extract on endothelial function and endothelial progenitor cells in overweight and obese individuals," Nutrition, vol. 31, no. 9, pp. 1131-1135, 2015.

[90] C.-R. Bae, Y.-K. Park, and Y.-S. Cha, "Quercetin-rich onion peel extract suppresses adipogenesis by down-regulating adipogenic transcription factors and gene expression in 3T3-L1 adipocytes," Journal of the Science of Food and Agriculture, vol. 94, no. 13, pp. 2655-2660, 2014.

[91] J. Moon, H.-J. Do, O. Y. Kim, and M.-J. Shin, “Antiobesity effects of quercetin-rich onion peel extract on the differentiation of 3T3-L1 preadipocytes and the adipogenesis in high fat-fed rats," Food and Chemical Toxicology, vol. 58, pp. 347-354, 2013.

[92] G. Saravanan and P. Ponmurugan, "Antidiabetic effect of Sallylcysteine: effect on thyroid hormone and circulatory antioxidant system in experimental diabetic rats," Journal of Diabetes and Its Complications, vol. 26, no. 4, pp. 280-285, 2012.

[93] N. K. Sambu, R. T. Kashinath, and J. G. Ambekar, "Effect of diallyl disulphide on diabetes induced dyslipidemia in male albino rats," Journal of Clinical and Diagnostic Research, vol. 9, no. 4, pp. BF01-BF03, 2015.

[94] F. Younis, D. Mirelman, A. Rabinkov, and T. Rosenthal, "Sallyl-mercapto-captopril: a novel compound in the treatment of cohen-rosenthal diabetic hypertensive rats," Journal of Clinical Hypertension, vol. 12, no. 6, pp. 451-455, 2010.

[95] M. S. H. Akash, K. Rehman, and S. Chen, "Spice plant Allium cepa: dietary supplement for treatment of type 2 diabetes mellitus," Nutrition, vol. 30, no. 10, pp. 1128-1137, 2014.

[96] J.-J. Lin, T. Chang, W.-K. Cai et al., "Post-injury administration of allicin attenuates ischemic brain injury through sphingosine kinase 2: in vivo and in vitro studies," Neurochemistry International, vol. 89, pp. 92-100, 2015.

[97] S. T. Ji, M.-S. Kim, H. R. Park et al., "Diallyl disulfide impairs hippocampal neurogenesis in the young adult brain," Toxicology Letters, vol. 221, no. 1, pp. 31-38, 2013.
[98] Y. Guo, K. Zhang, Q. Wang et al., "Neuroprotective effects of diallyl trisulfide in SOD1-G93A transgenic mouse model of amyotrophic lateral sclerosis," Brain Research, vol. 1374, pp. 110115, 2011.

[99] D. Y. Yoo, W. Kim, S. M. Nam et al., "Neuroprotective effects of Z-ajoene, an organosulfur compound derived from oilmacerated garlic, in the gerbil hippocampal CA1 region after transient forebrain ischemia," Food and Chemical Toxicology, vol. 72, pp. 1-7, 2014.

[100] G. Luo, Y. N. Huang, J. J. Wang et al., "Flavanoids extracted from onion inhibited activation of microglia and release of proinflammatory factors around the hematoma in ICH model rats," Chinese Journal of Integrative Medicine, vol. 36, no. 7, pp. 854-860, 2016.

[101] K. Selvakumar, R. L. Prabha, K. Saranya, S. Bavithra, G. Krishnamoorthy, and J. Arunakaran, "Polychlorinated biphenyls impair blood-brain barrier integrity via disruption of tight junction proteins in cerebrum, cerebellum and hippocampus of female Wistar rats: neuropotential role of quercetin," Human and Experimental Toxicology, vol. 32, no. 7, pp. 706-720, 2013.

[102] T. Y. Mirabeau and E. S. Samson, "Effect of Allium cepa and Allium sativum on some immunological cells in rats," African Journal of Traditional, Complementary and Alternative Medicines, vol. 9, no. 3, pp. 374-379, 2012.

[103] K. H. Kyung, "Antimicrobial properties of allium species," Current Opinion in Biotechnology, vol. 23, no. 2, pp. 142-147, 2012.

[104] D. Wallock-Richards, C. J. Doherty, L. Doherty et al., "Garlic revisited: antimicrobial activity of allicin-containing garlic extracts against Burkholderia cepacia complex," PLoS ONE, vol. 9, no. 12, Article ID e112726, 2014.

[105] M. C. H. Gruhlke, B. Hemmis, U. Noll, R. Wagner, H. Lühring, and A. J. Slusarenko, "The defense substance allicin from garlic permeabilizes membranes of Beta vulgaris, Rhoeo discolor, Chara corallina and artificial lipid bilayers," Biochimica et Biophysica Acta, vol. 1850, no. 4, pp. 602-611, 2015.

[106] S. Casella, M. Leonardi, B. Melai, F. Fratini, and L. Pistelli, "The role of diallyl sulfides and dipropyl sulfides in the in vitro antimicrobial activity of the essential oil of garlic, Allium sativum L., and leek, Allium porrum L.," Phytotherapy Research, vol. 27, no. 3, pp. 380-383, 2013.

[107] M. Sadeghi, B. Zolfaghari, M. Senatore, and V. Lanzotti, "Spirostane, furostane and cholestane saponins from Persian leek with antifungal activity," Food Chemistry, vol. 141, no. 2, pp. 1512-1521, 2013.

[108] Y. Wu, Y. He, and X. Ge, "Functional characterization of the recombinant antimicrobial peptide Trx-Ace-AMP1 and its application on the control of tomato early blight disease," Applied Microbiology and Biotechnology, vol. 90, no. 4, pp. 13031310, 2011.

[109] K.-S. Chung, S.-J. Shin, N. Y. Lee et al., "Anti-proliferation effects of garlic (Allium sativum L.) on the progression of benign prostatic hyperplasia," Phytotherapy Research, vol. 30, no. 7, pp. 1197-1203, 2016.

[110] C. S. Charron, H. D. Dawson, G. P. Albaugh et al., "A single meal containing raw, crushed garlic influences expression of immunity- and cancer-related genes in whole blood of humans," The Journal of Nutrition, vol. 145, no. 11, pp. 2448-2455, 2015.

[111] F. Jafarpour-Sadegh, V. Montazeri, A. Adili, A. Esfehani, M. Rashidi, and S. Pirouzpanah, "Consumption of fresh yellow onion ameliorates hyperglycemia and insulin resistance in 
breast cancer patients during doxorubicin-based chemotherapy: a randomized controlled clinical trial," Integrative Cancer Therapies, 2016.

[112] A. Sahebkar, C. Serban, S. Ursoniu, and M. Banach, "Effect of garlic on plasma lipoprotein(a) concentrations: a systematic review and meta-analysis of randomized controlled clinical trials," Nutrition, vol. 32, no. 1, pp. 33-40, 2016.

[113] R. Varshney and M. J. Budoff, "Garlic and heart disease," Journal of Nutrition, vol. 146, no. 2, pp. 416S-421S, 2016.

[114] K.-K. Lau, Y.-H. Chan, Y.-K. Wong et al., "Garlic intake is an independent predictor of endothelial function in patients with ischemic stroke," The Journal of Nutrition, Health \& Aging, vol. 17, no. 7, pp. 600-604, 2013.

[115] L. Supakul, H. Pintana, N. Apaijai, S. Chattipakorn, K. Shinlapawittayatorn, and N. Chattipakorn, "Protective effects of garlic extract on cardiac function, heart rate variability, and cardiac mitochondria in obese insulin-resistant rats," European Journal of Nutrition, vol. 53, no. 3, pp. 919-928, 2014.

[116] T. N. Khatua, R. Adela, and S. K. Banerjee, "Garlic and cardioprotection: insights into the molecular mechanisms," Canadian Journal of Physiology and Pharmacology, vol. 91, no. 6, pp. 448458, 2013.

[117] S. Park, M.-Y. Kim, D. H. Lee et al., "Methanolic extract of onion (Allium cepa) attenuates ischemia/hypoxia-induced apoptosis in cardiomyocytes via antioxidant effect," European Journal of Nutrition, vol. 48, no. 4, pp. 235-242, 2009.

[118] M. A. Vazquez-Prieto, C. Rodriguez Lanzi, C. Lembo, C. R. Galmarini, and R. M. Miatello, "Garlic and onion attenuates vascular inflammation and oxidative stress in fructose-fed rats," Journal of Nutrition and Metabolism, vol. 2011, Article ID 475216, 7 pages, 2011.

[119] B. He, J. Hao, W. Sheng et al., "Fistular onion stalk extract exhibits anti-atherosclerotic effects in rats," Experimental and Therapeutic Medicine, vol. 8, no. 3, pp. 785-792, 2014.

[120] D. Soleimani, Z. Paknahad, G. Askari, B. Iraj, and A. Feizi, "Effect of garlic powder consumption on body composition in patients with nonalcoholic fatty liver disease: a randomized, double-blind, placebo-controlled trial," Advanced Biomedical Research, vol. 5, article no. 2, 2016.

[121] R. Wang, Y. Fang, L. P. Xiao et al., "Effect of garlic on body mass index and serum lipids in elderly patients with hyperlipidemia," Chinese Heart Journal, vol. 28, no. 5, pp. 565-567, 2016.

[122] A. Qamar, A. Siddiqui, and H. Kumar, "Fresh garlic amelioration of high-fat-diet induced fatty liver in albino rats," Journal of the Pakistan Medical Association, vol. 65, no. 10, pp. 1102-1107, 2015.

[123] N. Aslani, M. H. Entezari, G. Askari, Z. Maghsoudi, and M. R. Maracy, "Effect of garlic and lemon juice mixture on lipid profile and some cardiovascular risk factors in people 30-60 years old with moderate hyperlipidaemia: a randomized clinical trial," International Journal of Preventive Medicine, vol. 7, no. 1, p. 95, 2016.

[124] H. Emamat, F. Foroughi, H. Eini-Zinab, M. Taghizadeh, M. Rismanchi, and A. Hekmatdoost, "The effects of onion consumption on treatment of metabolic, histologic, and inflammatory features of nonalcoholic fatty liver disease," Journal of Diabetes and Metabolic Disorders, vol. 15, no. 1, article no. 25, 2016.

[125] A. Hosseini and H. Hosseinzadeh, "A review on the effects of Allium sativum (Garlic) in metabolic syndrome," Journal of Endocrinological Investigation, vol. 38, no. 11, pp. 1147-1157, 2015.
[126] M.-J. Kim and H. K. Kim, "Effect of garlic on high fat induced obesity," Acta Biologica Hungarica, vol. 62, no. 3, pp. 244-254, 2011.

[127] S. Gautam, S. Pal, R. Maurya, and A. K. Srivastava, "Ethanolic extract of Allium cepa stimulates glucose transporter typ 4mediated glucose uptake by the activation of insulin signaling," Planta Medica, vol. 81, no. 3, pp. 208-214, 2015.

[128] C.-L. Liu, T.-C. Hsia, and M.-C. Yin, "S-Methyl cysteine enhanced survival of nerve growth factor differentiated PC12 cells under hypoxic conditions," Food and Function, vol. 5, no. 6, pp. 1125-1133, 2014.

[129] T. Imai, Y. Kosuge, K. Endo-Umeda et al., "Protective effect of S-allyl-l-cysteine against endoplasmic reticulum stress-induced neuronal death is mediated by inhibition of calpain," Amino Acids, vol. 46, no. 2, pp. 385-393, 2014.

[130] H. Zhou, Z. Qu, V. V. Mossine et al., "Proteomic analysis of the effects of aged garlic extract and its FruArg component on lipopolysaccharide-induced neuroinflammatory response in microglial cells," PLoS ONE, vol. 9, no. 11, Article ID e113531, 2014.

[131] B. Cemil, E. C. Gokce, R. Kahveci et al., "Aged garlic extract attenuates neuronal injury in a rat model of spinal cord ischemia/reperfusion injury," Journal of Medicinal Food, vol. 19, no. 6, pp. 601-606, 2016.

[132] S.-W. Hyun, M. Jang, S. W. Park, E. J. Kim, and Y.-S. Jung, "Onion (Allium cepa) extract attenuates brain edema," Nutrition, vol. 29, no. 1, pp. 244-249, 2013.

[133] S. Kenawy, G. F. Mohammed, S. Younes, and A. I. Elakhras, "Evaluation of TNF- $\alpha$ serum level in patients with recalcitrant multiple common warts, treated by lipid garlic extract," Dermatologic Therapy, vol. 27, no. 5, pp. 272-277, 2014.

[134] Q. Q. Zheng, T. Liu, K. Q. Xie et al., "Anti-influenza virus activities of garlic oil in mice model in vivo," Journal of Shandong University (Health Science), vol. 54, no. 7, pp. 23-27, 2016.

[135] D. Tan, Y. Zhang, L. Chen et al., "Decreased glycation and structural protection properties of $\gamma$-glutamyl-S-allyl-cysteine peptide isolated from fresh garlic scales (Allium sativum L.)," Natural Product Research, vol. 29, no. 23, pp. 2219-2222, 2015.

[136] S. H. S. El-Din, A.-N. A. Sabra, O. A. Hammam, F. A. Ebeid, and N. M. El-Lakkany, "Pharmacological and antioxidant actions of garlic and/or onion in non-alcoholic fatty liver disease (NAFLD) in rats," Journal of the Egyptian Society of Parasitology, vol. 44, no. 2, pp. 295-308, 2014.

[137] H. Luo, J. Huang, W.-G. Liao, Q.-Y. Huang, and Y.-Q. Gao, “The antioxidant effects of garlic saponins protect PC12 cells from hypoxia-induced damage," British Journal of Nutrition, vol. 105, no. 8, pp. 1164-1172, 2011.

[138] R. Tocmo, D. Liang, Y. Lin, and D. Huang, "Chemical and biochemical mechanisms underlying the cardioprotective roles of dietary organopolysulfides," Frontiers in Nutrition, vol. 2, article no. 1, 2015.

[139] R. Arreola, S. Quintero-Fabián, R. I. López-Roa et al., "Immunomodulation and anti-inflammatory effects of garlic compounds," Journal of Immunology Research, vol. 2015, Article ID 401630, 13 pages, 2015.

[140] E. De Gianni and C. Fimognari, "Anticancer mechanism of sulfur-containing compounds," Enzymes, vol. 37, pp. 167-192, 2015.

[141] D. Wu, Q. Hu, F. Ma, and Y. Z. Zhu, "Vasorelaxant effect of a new hydrogen sulfide-nitric oxide conjugated donor in isolated rat aortic rings through cGMP pathway," Oxidative Medicine and Cellular Longevity, vol. 2016, Article ID 7075682, 10 pages, 2016. 
[142] B. V. Nagpure and J.-S. Bian, "Interaction of hydrogen sulfide with nitric oxide in the cardiovascular system," Oxidative Medicine and Cellular Longevity, vol. 2016, Article ID 6904327, 16 pages, 2016.

[143] G. V. Velmurugan, H. Huang, H. Sun et al., "Depletion of $\mathrm{H}_{2} \mathrm{~S}$ during obesity enhances store-operated $\mathrm{Ca}^{2+}$ entry in adipose tissue macrophages to increase cytokine production," Science Signaling, vol. 8, no. 407, p. ra128, 2015.

[144] Y. Ju, A. Untereiner, L. Wu, and G. Yang, " $\mathrm{H}_{2} \mathrm{~S}$-induced Ssulfhydration of pyruvate carboxylase contributes to gluconeogenesis in liver cells," Biochimica et Biophysica Acta-General Subjects, vol. 1850, no. 11, pp. 2293-2303, 2015.

[145] K. K. Al-Qattan, M. Thomson, D. Jayasree, and M. Ali, "Garlic attenuates plasma and kidney ACE-1 and AngII modulations in early streptozotocin-induced diabetic rats: renal clearance and blood pressure implications," Evidence-based Complementary and Alternative Medicine, vol. 2016, Article ID 8142394, 11 pages, 2016.

[146] A. L. Al-Malki, "Inhibition of $\alpha$-glucosidase by thiosulfinate as a target for glucose modulation in diabetic rats," Evidence-Based Complementary and Alternative Medicine, vol. 2016, Article ID 7687915, 5 pages, 2016.

[147] S. H. Lee, E. J. Lee, K. H. Min et al., "Quercetin enhances chemosensitivity to gemcitabine in lung cancer cells by inhibiting heat shock protein 70 expression," Clinical Lung Cancer, vol. 16, no. 6, pp. e235-e243, 2015.

[148] L. G. Costa, J. M. Garrick, P. J. Roquè, and C. Pellacani, "Mechanisms of neuroprotection by quercetin: counteracting oxidative stress and more," Oxidative Medicine and Cellular Longevity, vol. 2016, Article ID 2986796, 10 pages, 2016.

[149] T. M. Henagan, W. T. Cefalu, D. M. Ribnicky et al., "In vivo effects of dietary quercetin and quercetin-rich red onion extract on skeletal muscle mitochondria, metabolism, and insulin sensitivity," Genes \& Nutrition, vol. 10, article no. 2, 2015.

[150] S.-Y. Lin, Y.-Y. Wang, W.-Y. Chen, Y.-H. Chuang, P.-H. Pan, and C.-J. Chen, "Beneficial effect of quercetin on cholestatic liver injury," Journal of Nutritional Biochemistry, vol. 25, no. 11, pp. 1183-1195, 2014.

[151] T. Oliveira, C. A. Figueiredo, C. Brito et al., "Allium cepa L. and quercetin inhibit RANKL/ porphyromonas gingivalis LPSinduced osteoclastogenesis by downregulating NF- $\kappa \mathrm{B}$ signaling pathway," Evidence-Based Complementary and Alternative Medicine, vol. 2015, Article ID 704781, 11 pages, 2015.

[152] I. Najmanová, M. Vopršálová, and P. Mladenka, "Vasodilatory activity of human quercitin metabolites," Free Radical Biology and Medicine, vol. 75, p. S43, 2014.

[153] B. K. Lee and Y.-S. Jung, "Allium cepa extract and quercetin protect neuronal cells from oxidative stress via PKC- $\varepsilon$ inactivation/ERK1/2 activation," Oxidative Medicine and Cellular Longevity, vol. 2016, Article ID 2495624, 9 pages, 2016.

[154] Y. Wan, M. H. Tang, X. C. Chen, L. J. Chen, Y. Q. Wei, and Y. S. Wang, "Inhibitory effect of liposomal quercetin on acute hepatitis and hepatic fibrosis induced by concanavalin A," Brazilian Journal of Medical and Biological Research, vol. 47, no. 8, pp. 655-661, 2014. 


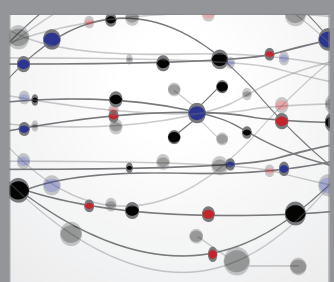

The Scientific World Journal
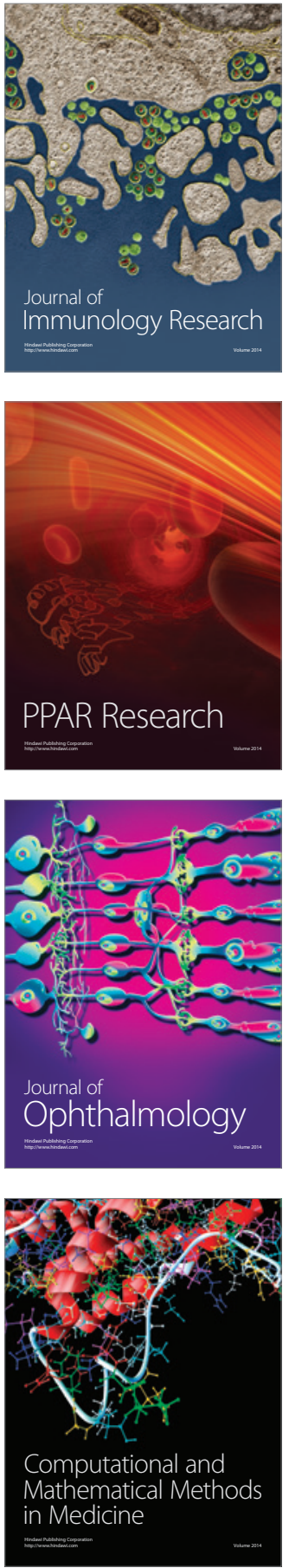

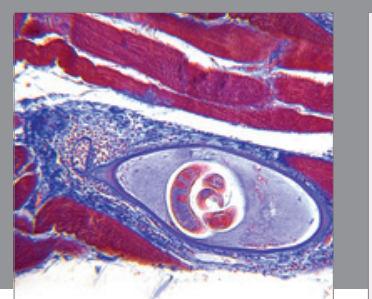

Gastroenterology Research and Practice
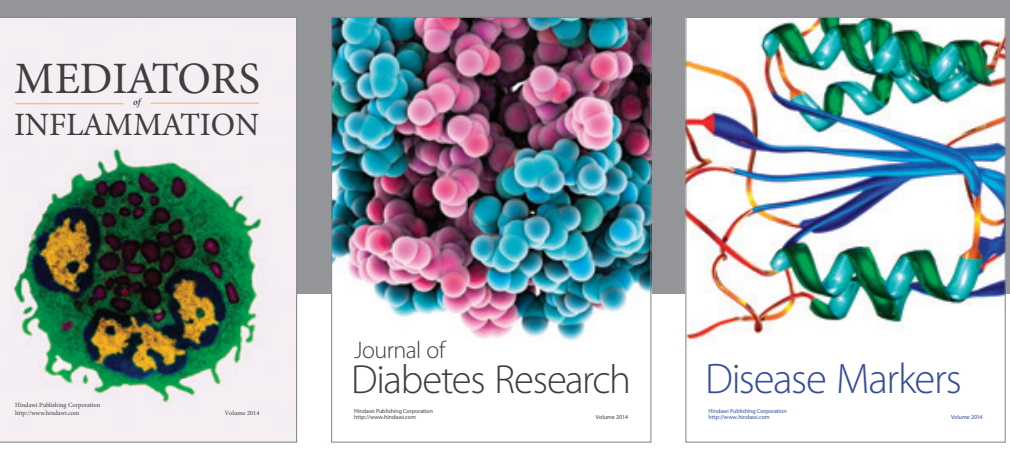

Disease Markers

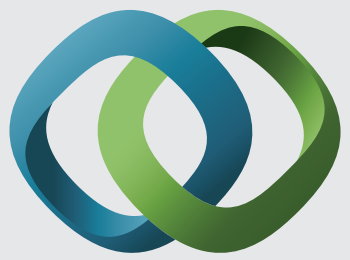

\section{Hindawi}

Submit your manuscripts at

https://www.hindawi.com
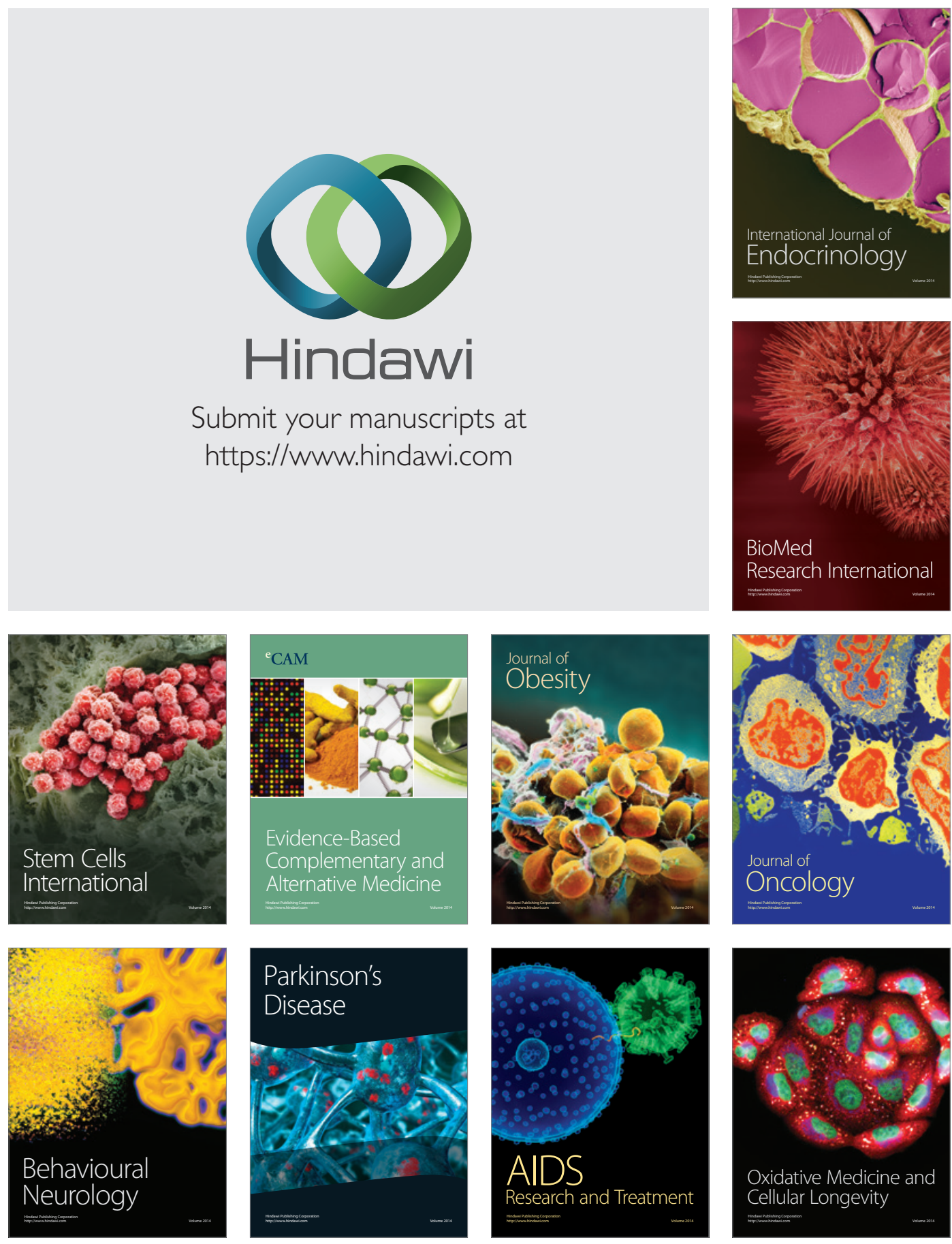